\title{
Outlet obstruction constipation (anismus) managed by biofeedback
}

\author{
B M Kawimbe, M Papachrysostomou, N R Binnie, N Clare, A N Smith
}

\begin{abstract}
Fifteen subjects presenting with intractable constipation due to obstructive defecation, mean (SEM) duration $8.8(1.8)$ years, had the inappropriate contraction and electromyographic changes in the pelvic floor muscles and external anal sphincter typical of this condition. An electromyographically derived index was used to grade its severity. A self applied biofeedback device was used to allow electromyographic recording of the abnormal external anal sphincter. The subjects were encouraged to reduce the abnormal electromyographic activity on straining after instruction and training. The procedure was intended as a relearning process in which the nonrelaxing activity of the pelvic floor was gradually suppressed. Biofeedback training was maintained on a domiciliary basis for a mean time of 3.1 weeks and resulted in a significant reduction in the anismus index (mean (SEM) $69.9(7.8) \%$ before biofeedback, mean 14 (3.9)\% after biofeedback, $\mathrm{p}<0.01)$. There was an associated reduction in the time spent straining at stool and in the difficulty of defecation and an increased frequency of defecation. Defecatory video proctograms in six subjects showed improvements in the anorectal angle during straining and evacuation. The clinical benefit to the patients persisted after a mean follow up of $6 \cdot 2$ months.
\end{abstract}

Inappropriate contraction of the posterior portion of the pelvic floor musculature when straining to defecate can produce a form of constipation which is caused by the anorectal 'outlet' obstruction which ensues. This implies failure of the inhibition of the pelvic floor muscle which occurs in normal defecation together with a spasm of the pelvic floor which creates the conditions for the severe constipation of this state known as anismus. ${ }^{1-3}$ The affected subjects strain excessively at stool with the higher centres unaware of the incoordination of the pelvic floor. The inappropriate external anal sphincter contraction can be detected by modern non-invasive electromyographic techniques. ${ }^{+}$The claim has been made that biofeedback training can promote defecation by restoring the capability of inhibiting the anomalous contraction of the pelvic floor. This is done by learning to suppress the activity of the non-relaxing part of it. ${ }^{\prime}$

A self applied electromyographic device, Myotron 120 (Physiological Feedback Systems, Vijftig Bunderweg 1, Dorst (NB), The Netherlands) allows the subject to see or hear the electromyographic response of the external anal sphincter muscle during straining, and the feedback of biological information is the basis of the training technique. ${ }^{5}$ The aim of the study was to assess the effect of using such self applied recording as a biofeedback means of domiciliary treatment in a group of subjects with anismus using subjective improvement and objective evidence as measures of the outcome.

\section{Patients}

Fifteen subjects, 12 women and three men, median age 45 years, range 22-76 years, presented with intractable constipation and excessive straining at stool due to difficulty in evacuating the rectum. The mean (SEM) duration of the presenting complaint was $8 \cdot 8(7 \cdot 1)$ years. All subjects had some perineal discomfort at defecation and one had an anterior rectal mucosal prolapse. Each underwent proctoscopy and rigid sigmoidoscopy to exclude other associated pathology such as rectal prolapse or solitary rectal ulceration. All were asked to stop taking their medication at the start of treatment.

\section{Methods}

\section{ANORECTAL MANOMETRY}

Standard manometric methods were used to measure the length of the anal sphincter high pressure zone, the maximum resting pressure, and the rectosphincteric reflex relaxation of the internal sphincter. ${ }^{6}$ A continuous infusion proctometrogram technique was used to assess sensory awareness, maximal rectal capacity, and the rectal compliance. ${ }^{7}$ In a further test the proctometrogram balloon was filled to the level of sensory awareness and the subject invited to attempt to expel the balloon voluntarily. This was repeated as a training exercise up to 10 times in each subject with the object of increasing the subject's rectal sensory awareness.

\section{ELECTROPHYSIOLOGY}

The pudendoanal reflex latency ${ }^{8}$ and the external anal sphincter motor unit potential duration was measured using a standard concentric needle electrode technique.'

\section{DETECTION OF ANISMUS}

The subject lay in the left lateral position with a ground electrode wrapped round the right thigh. An anal plug electrode ${ }^{4}$ connected to an isolated electromyographic integrator was placed in the anal canal. The resting electromyography was recorded from the external anal sphincter before the squeeze recording and the strain recording after bearing down as if at stool. An anismus 
TABLE I Anorectal manometry and electromyographic results before and after biofeedback and at later follow up in 15 subjects (mean (SEM))

\begin{tabular}{|c|c|c|c|}
\hline Test & $\begin{array}{l}\text { Before } \\
\text { biofeedback }\end{array}$ & $\begin{array}{l}\text { After } \\
\text { biofeedback }\end{array}$ & $\begin{array}{l}\text { Follow up } \\
\text { (months) }\end{array}$ \\
\hline $\begin{array}{l}\text { High pressure zone in anal canal }(\mathrm{cm}) \\
\text { Maximum resting pressure in the anal canal }\left(\mathrm{cm} \mathrm{H}_{2} \mathrm{O}\right) \\
\text { Rectosphincteric reflex }\left(\mathrm{cm} \mathrm{H}_{2} \mathrm{O}\right) \\
\text { Maximum rectal volume of capacity }(\mathrm{ml})\end{array}$ & $\begin{array}{r}3 \cdot 1(0 \cdot 2) \\
92 \cdot 3(5 \cdot 1) \\
66 \cdot 4(4 \cdot 6) \\
448(21)\end{array}$ & $\begin{array}{l}3 \cdot 0(0 \cdot 2) \\
9 \cdot 14(5 \cdot 6) \\
66 \cdot 2(4 \cdot 5) \\
443(22)\end{array}$ & $\begin{array}{r}3 \cdot 1(0 \cdot 2) \\
92 \cdot 9(5 \cdot 5) \\
66 \cdot 1(3 \cdot 8) \\
445(23)\end{array}$ \\
\hline $\begin{array}{l}\text { Rectal compliance ratio of volume/intraluminal } \\
\text { pressure }\left(\mathrm{ml} / \mathrm{cm} \mathrm{H}_{2} \mathrm{O}\right) \\
\text { Pudendo anal reflex latency (ms) }\end{array}$ & $\begin{array}{r}7 \cdot 6(0 \cdot 4) \\
42 \cdot 3(1 \cdot 7)\end{array}$ & $\begin{array}{r}7 \cdot 6(0 \cdot 5) \\
42 \cdot 4(1 \cdot 7)\end{array}$ & $\begin{array}{r}7 \cdot 7(0 \cdot 5) \\
42 \cdot 5(1 \cdot 8)\end{array}$ \\
\hline $\begin{array}{l}\text { Motor unit potential duration of the external anal } \\
\text { sphincter (ms) }\end{array}$ & $8 \cdot 8(0 \cdot 6)$ & $8 \cdot 7(0 \cdot 7)$ & $8.9(0.8)$ \\
\hline
\end{tabular}

index was calculated from strain electromyographic voltage-rest electromyographic voltage $\times$ squeeze recording-rest electromyographic voltage $\times 100 .{ }^{10}$

\section{ELECTROMYOGRAPHIC BIOFEEDBACK}

The subjects came to the anorectal motility laboratory for training and met the doctor and the technician carrying out the study. They were shown a diagrammatic representation of their problem and the objectives of the biofeedback treatment were explained. The anal plug electrode was placed in the anal canal and connected to the biofeedback device. The Myotron was calibrated and the resting electromyographic recording was noted. The subjects now contracted the external sphincter and recorded the squeeze, which was displayed as $\mu \mathrm{V}$ in excess of the original resting recording. Then, bearing down as if at stool, the subjects took particular note of the straining recording. The electromyographic activity could also be monitored continuously by means of a built in loud speaker in which the frequency of the sound waves varied proportionately with the electromyographic level. At successive straining attempts and by altering the method of straining as required to become purposeful, the subject tried to relax the pelvic floor and to reduce the straining recording down to or below the resting recording and thus correct the anismus dysfunction by restoring the normal defecation inhibition of the pelvic floor.

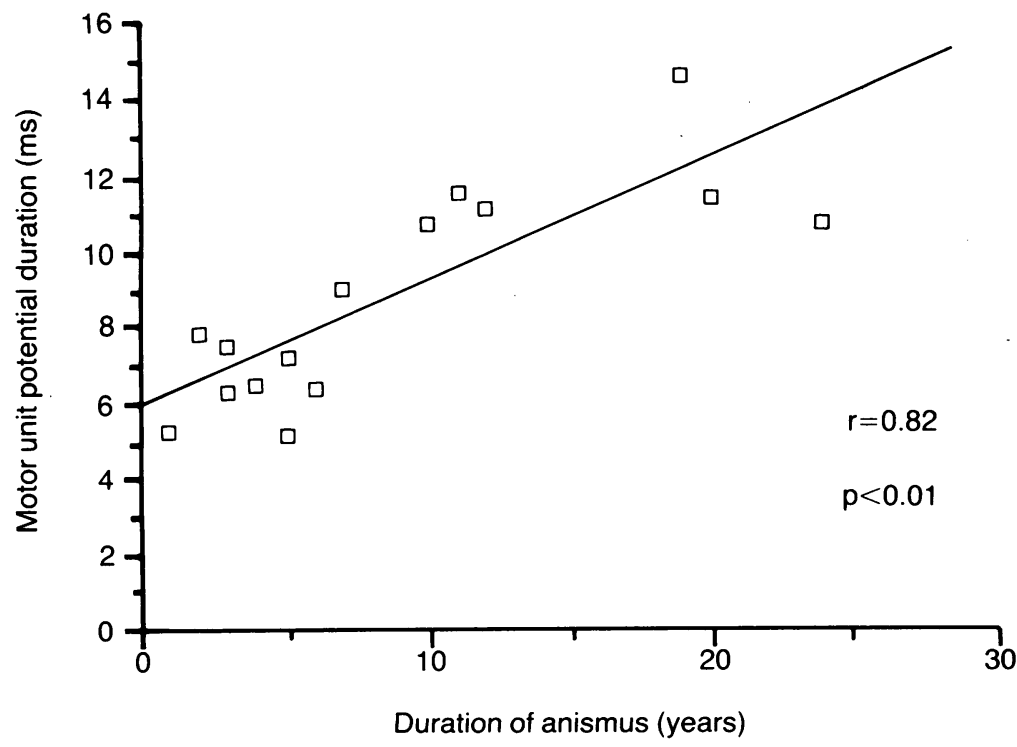

Figure 1: Correlation of external anal sphincter mean motor unit potential duration and duration of symptoms of anismus.
Subjects then took the device home with the aim of using it for two sessions per day. They were to attempt defecation only on the morning occasion, the second session being a reinforcement exercise. The Myotron had a simple set of instructions attached to it since some subjects were uncertain of some of the steps and details of the procedure or became confused by the sequence of events.

The duration of domiciliary biofeedback treatment was in multiples of two weeks, depending on the subjects' symptoms and whether they thought they would benefit from continuing biofeedback. The group was, on the whole, highly motivated and all went through the learning exercise and period of training. They particularly appreciated the availability at all times of the female technician in the team. Eight subjects used the device for two weeks, six for four weeks, and one for six weeks. They also kept a diary record of the number of stools passed per week, the time spent straining at stool, the degree of difficulty in passing stools, and noted any perineal pain or discomfort. The last two symptoms were scored as indices on an analogue scale of $0,1=$ mild, $2=$ moderate, $3=$ severe. The subjects who had begun to keep a diary of these events before starting biofeedback continued to do so throughout the treatment and continued for two weeks afterwards before attending the laboratory for review.

\section{RADIOLOGY}

Video-proctograms were performed using a mixture of barium potato mash mixture for six subjects. The anorectal angle was measured at rest, on squeezing to contract the sphincters, and on straining (bearing down) to simulate evacuation.

\section{FOLLOW UP}

All subjects were reviewed between three and six months after the assessment at the end of biofeedback treatment when the anorectal function tests were repeated. Two subjects were seen again at one year and a further two were reviewed at over 15 months, giving an overall mean (SEM) follow up time of $6 \cdot 2(4 \cdot 6)$ months.

\section{STATISTICS}

Statistical analysis was performed on the data using the non-parametric Wilcoxon signed rank test for paired data.

\section{Results}

ANORECTAL MANOMETRY

There were no significant differences in the results of the standard anorectal manometric investigations before and after biofeedback or between biofeedback and follow up tests (Table I).

ANORECTAL NEUROPHYSIOLOLOGY

The pudendoanal reflex was present in all subjects with a mean (SEM) latency of $42 \cdot 3(1 \cdot 7) \mathrm{ms}$ (Table I). The mean motor unit potential 
TABLE II Results of anismus index plus records from diaries of 15 subjects before and after biofeedback and at later follow up (mean (SEM))

\begin{tabular}{lrrr}
\hline Test & $\begin{array}{l}\text { Before } \\
\text { biofeedback }\end{array}$ & $\begin{array}{l}\text { After } \\
\text { biofeedback }\end{array}$ & $\begin{array}{l}\text { Follow up } \\
\text { (months) }\end{array}$ \\
\hline Anismus index & $69 \cdot 9(7 \cdot 8)$ & $14 \cdot 0(3 \cdot 9)$ & $14 \cdot 6(3 \cdot 7)$ \\
Perineal pain at defecation & $2 \cdot 3(0 \cdot 2)$ & $0 \cdot 5(0 \cdot 2)$ & $0 \cdot 4(0 \cdot 2)$ \\
Difficulty at defecation & $2 \cdot 8(0 \cdot 1)$ & $1 \cdot 1(0 \cdot 2)$ & $0 \cdot 6(0 \cdot 1)$ \\
Time spent straining at stool & $12 \cdot 7(1 \cdot 2)$ & $5 \cdot 6(0 \cdot 8)$ & $4 \cdot 5(0 \cdot 5)$ \\
No of bowel motions per week & $5 \cdot 2(0 \cdot 8)$ & $8 \cdot 8(1 \cdot 0)$ & $7 \cdot 4(0 \cdot 7)$ \\
Ability to expel rectal balloon or balloon explusion test & 2 & 13 & 11 \\
\hline
\end{tabular}

duration of the external anal sphincters was $8 \cdot 8$ $(0 \cdot 6) \mathrm{ms}$. The widest motor unit potentials were in subjects with the longest history of anismus (Fig 1) $(\mathrm{r}=0.82, \mathrm{p}<0.01)$.

\section{ANISMUS AND BIOFEEDBACK}

The anismus index before and after biofeedback and at the latest follow up is given in Table II,

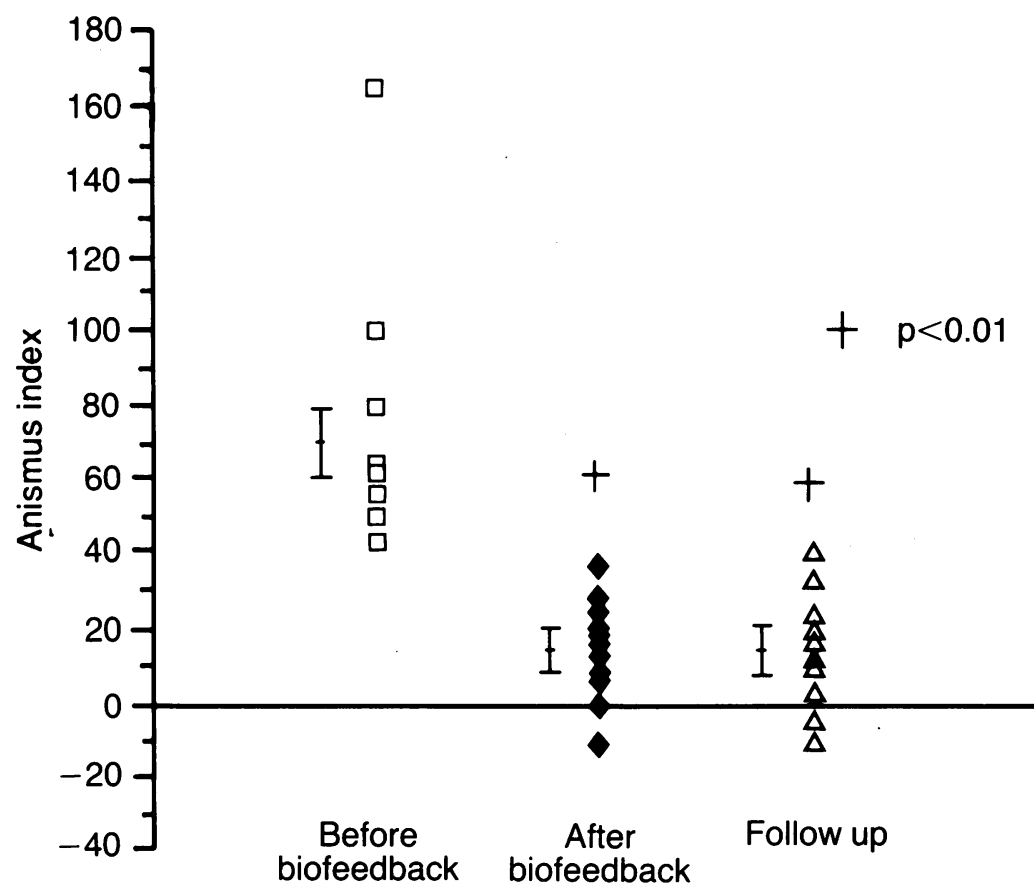

Figure 2: Anismus index before and after biofeedback (mean (SEM)).

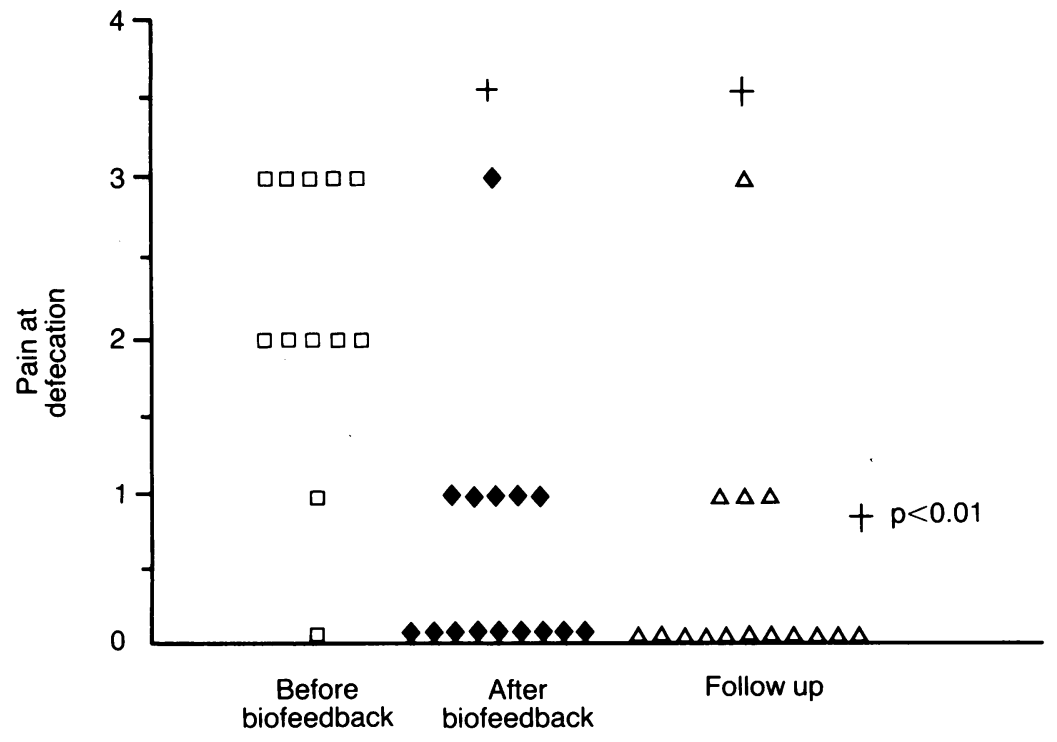

Figure 3: Degree of pain at defecation. which also gives the data for stool frequency, perineal discomfort at defecation, difficulty with defecation, and time spent straining at stool before and after biofeedback training. The anismus index fell significantly (mean from $69.9(7 \cdot 8)$ to $14.0(3.9) ; \mathrm{p}<0.01$ ) (Fig 2). The analogue scale value for pain at defecation, the degree of difficulty of defecation, and the time spent straining (Figs 3-5) were all significantly decreased $(p<0.01)$, though the overall time spent at defecation was increased (Fig 6). The increase in the frequency of defecation was significant after biofeedback $(p<0.01)$ (Fig 7) but this change did not persist at follow up. Before biofeedback training only two subjects could expel the rectal balloon, whereas after biofeedback training 13 out of 15 could do so.

\section{RADIOLOGY}

In the six subjects examined by radiology the anorectal angle before biofeedback was made more acute by squeezing movements (at rest $82^{\circ}$ average, postsqueeze $67.5^{\circ}$ average) and obtuse on straining $\left(95^{\circ}\right.$ average). After biofeedback the effect of squeezing $\left(88^{\circ}\right.$ at rest, $62.5^{\circ}$ postsqueeze) still made the anorectal angle acute but the angle on straining became $104 \cdot 5^{\circ}$ on average. Five of the subjects could not expel the barium potato mixture when examined before biofeedback training. Only three could do so when examined by the same method after biofeedback despite the $10^{\circ}$ increment caused by the opening out of the anorectal angle which had formerly acted as an obstacle to evacuation. All three subjects who, after biofeedback, failed to expel contrast medium, however, claimed that this was caused by lack of privacy during the examination and that they had no similar problem at home.

\section{Discussion}

Anorectal outlet obstruction due to anismus or anismus like activity follows the loss of the normal inhibition of the pelvic floor that occurs while straining to defecate. ${ }^{11}$ In addition to their abnormal electromyographic responses the subjects in this series presented with intractable constipation. A sample of these showed typical radiological signs of this condition such as the acute anorectal angle becoming more acute with squeezing actions of the external sphincter and pelvic floor muscle combined with the same angle failing to open out to an obtuse angle with straining or bearing down movements to prepare for the evacuation of the faecal bolus. Radiological verification of these effects and the consistently abnormal electromyographic changes showed that the patients with intractable constipation had anismus or were in an animus like state. We know that the electromyographic changes alone may not be consistent and are also found in other conditions such as severe constipation, perineal pain, and the solitary rectal ulcer syndrome. ${ }^{12}$

The failure of the pelvic floor and external anal sphincter to relax is compounded by their inappropriate contraction. ${ }^{13}$ The descriptive term 'anismus' has been applied to this part of the phenomenon ${ }^{3}$ and is suspected if the history 


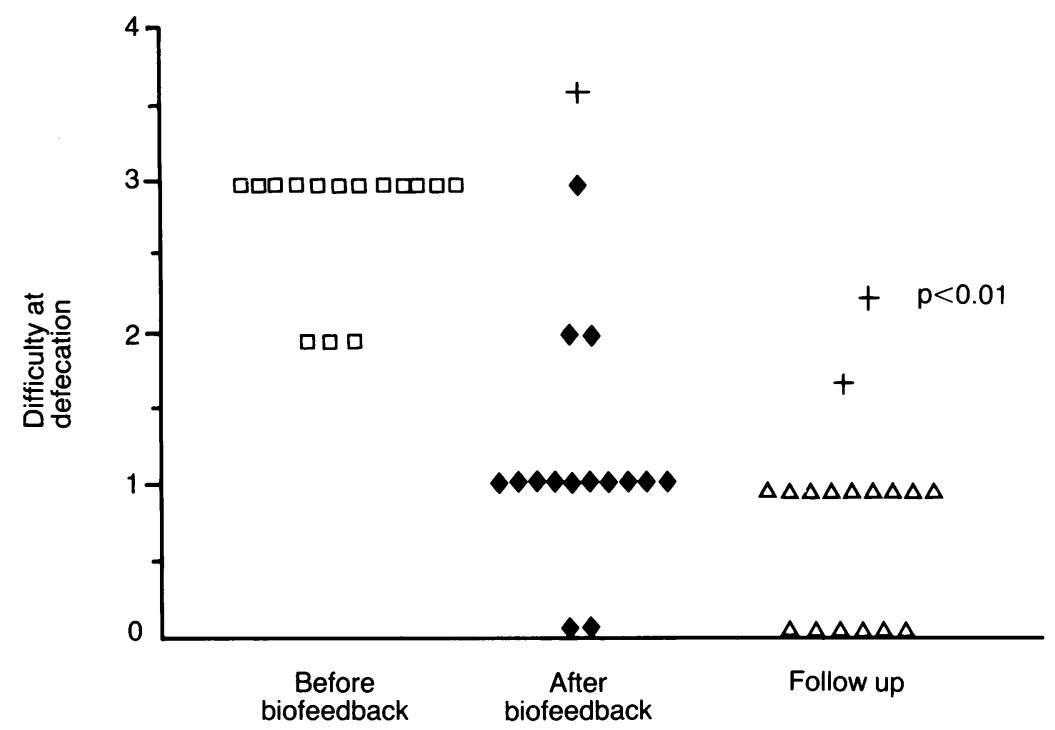

Figure 4: Degree of difficulty at defecation.

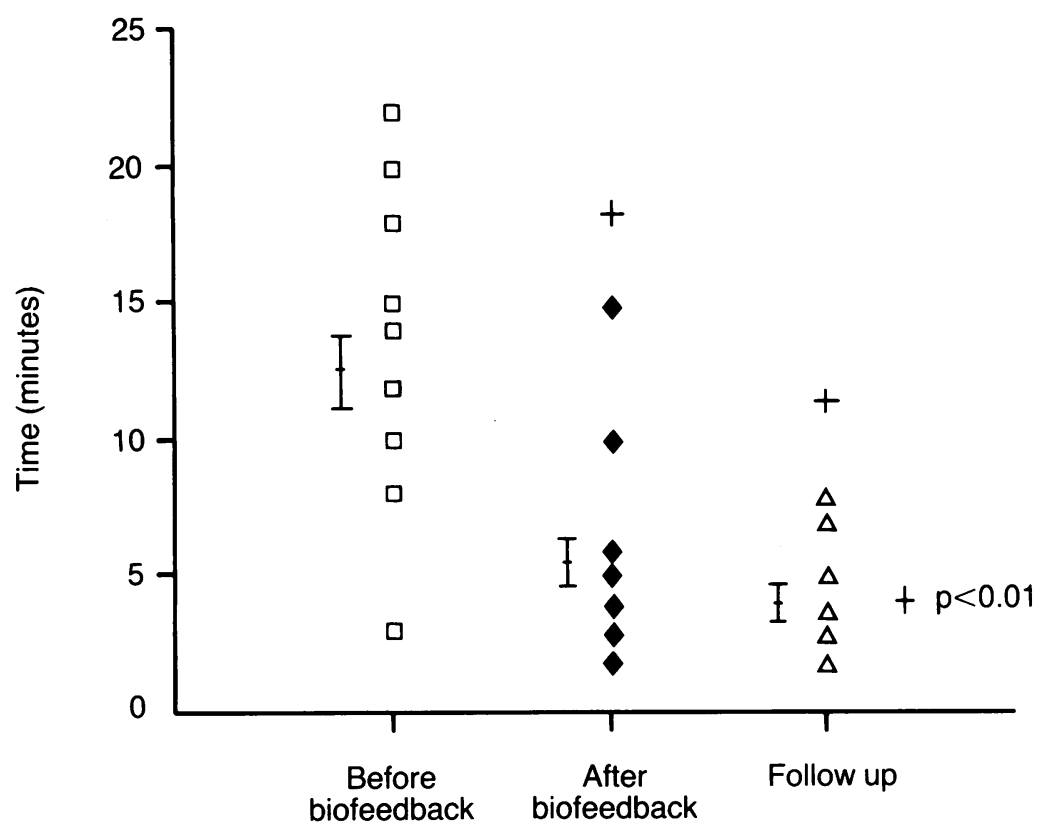

Figure 5: Time spent straining at stool (mean (SEM)).

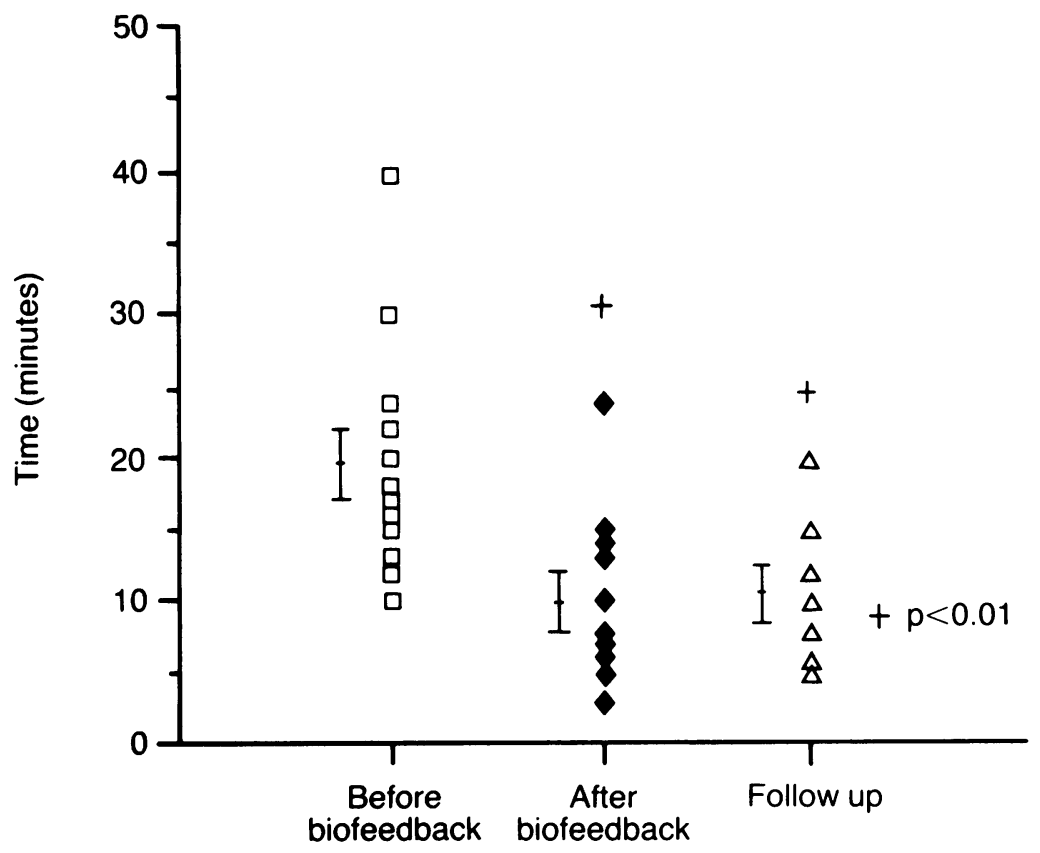

Figure 6: Time spent on the toilet (mean (SEM)). includes excessive straining during defecation with difficulty in evacuating the rectum, often requiring self digitation of the rectum. ${ }^{14}$ The condition is confirmed objectively by anorectal manometry which initially shows a rise in sphincter pressure with straining ${ }^{2}$ and the electromyographic studies showing increased activity with straining. ${ }^{11}$ Defecography shows an accentuation of the puborectalis indentation at the anorectal angle with straining. ${ }^{15}$

Electromyographic changes suggesting anismus were detected in all subjects using a surface anal plug electrode to record the abnormal electromyographic changes indicative of the inappropriate contraction of the pelvic floor muscle when straining. There was a significant correlation between the duration of the presenting complaint of excessive straining and the mean motor potential duration of the external sphincter. This implies that straining caused a traction injury to the pudendal nerve ${ }^{15}$ and that some reinnervation was occurring, which in turn prolonged the mean motor potential duration of the affected muscle. ${ }^{916}$

Attempts to overcome the obstructive effects of the non-relaxing puborectalis muscle at defecation in true anismus have been varied. Pharmacological blockade of the sympathetic innervation has been tried when pelvic floor spasm affects the bladder. Puborectalis relaxation by local injection of botulinus toxin has been shown to be effective in correcting anismus, ${ }^{17}$ but the effect is relatively short lived and needs to be repeated. Various surgical methods such as partial division of the puborectalis muscle have been advocated ${ }^{18}{ }^{19}$ to allow obstructed defecation to proceed, but against this approach is the overriding importance of maintaining continence.

As anismus subjects are unaware of the incoordination of the pelvic floor, biofeedback offers a simple and minimally invasive technique for relearning how to suppress the non-relaxation of the pelvic floor. ${ }^{5}$ The Myotron 120 device is ideally suited for retraining anismus subjects. ${ }^{+}$It is small, compact, easily operated, and relatively inexpensive. An experienced tutor needs to instruct the subjects on what they are required to do and aiming to achieve with the device. The clinical aim is trouble free defecation, which is not always accompanied by complete resolution of the anismus muscle abnormality.

In our series a minor degree of electromyographic anismus remained and was acceptable as it was asymptomatic. The subjects maintained a reduction in the anismus index over a two year period. When tested after the biofeedback training period the fall in the anismus index was accompanied by less time spent in straining, more bowel movements per week, and less perineal pain and discomfort. They more readily expelled a balloon bolus from the rectum and generally spent more time over defecation, feeling that there was clinical improvement in their defecation capability.

Our radiological studies confirm that the anorectal angle is acute in anismus subjects and becomes increasingly so on contraction of the sphincters as in squeezing movements, nor does this angle open out in the mimicked defecation of 


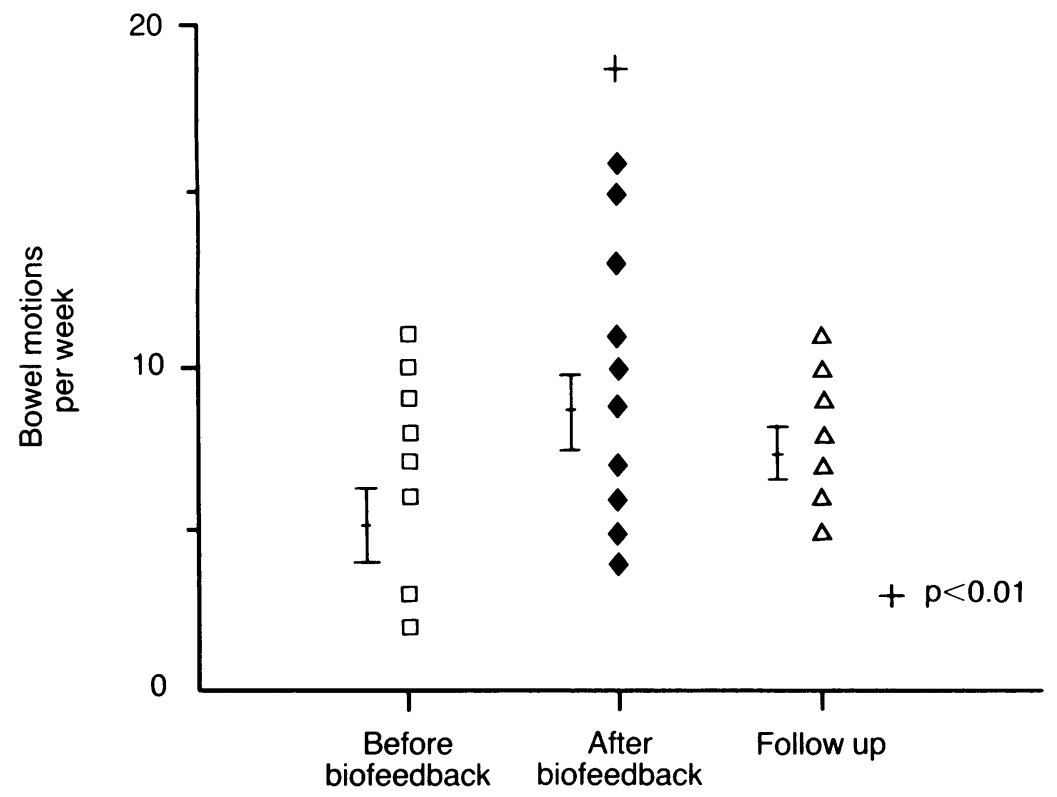

Figure 7: Number of bowel motions per week (mean (SEM)).

straining or bearing down. After biofeedback treatment the anorectal angle significantly 'opened out' on straining. Some subjects found it difficult to expel the barium mixture, unlike the balloon in the laboratory experiments, whether due to embarrassment or some element of the anismus like state continuing. In patients with defecation problems defecography may detect anatomical abnormalities and give some insight into the pathophysiology of defecation, but has been thought to lack clinical relevance in establishing the diagnosis and progress. ${ }^{20}$

What remains is to determine the longterm duration of the improvement and to acquire more information about the mechanism of the anismus defect as well as the nature of other anismus like states. It is not known how biofeedback reverses the anismus state or whether biofeedback training abolishes it directly or promotes indirectly a compensatory phenomenon.
BMK was supported by a Janssen Pharmaceutical Research Fellowship and MP is supported by a Scottish Home and Health Department Clinical and Biomedical Research Grant (K/MRS 5001202). NRB was supported by a Scottish Hospitals Endowment Research Trust Grant (No 720).

1 Bleijenberg G, Kuijpers HC. Treatment of spastic pelvic floor syndrome with biofeedback. Dis Colon Rectum 1987; 30 . 108-11.

2 Wasserman IF. Pubo-rectalis syndrome (rectal stenosis due to anorectal spasm). Dis Colon Rectum 1964; 7: 87.

3 Preston DM, Lennard-Jones JE. Anismus in chronic constipation. Dig Dis Sci 1985; 30: 413-8.

4 Binnie NR, Kawimbe BM, Papachrysostomou M, Clare N, Smith AN. A non-invasive anal plug electrode: the importance of the orientation of the electrode plates in recording the EMG. Int f Colorectal Dis 1991; 6: 5-8.

5 Almy TP, Corson JA. Biofeedback - the light at the end of the tunnel. Gastroenterology 1979; 76: 874-6.

6 Varma JS, Smith AN. Anorectal profilometry with the microtransducer. Br f Surg 1984; 71: 285-9.

7 Varma JS, Smith AN. Reproducibility of the proctometrogram. Gut 1986; 27: 288-92.

8 Varma JS, Smith AN, McInnes A. Electrophysiological observations on the human pudendo-anal reflex. $\mathcal{F}$ Neurol Neurosurg Psychiatry 1986; 49: 1411-6.

9 Bartolo DCC, Jarratt JA, Read NW. The use of conventional EMG to assess external anal sphincter neuropathy in man. f Neurol Neurosurg Psvchiatry 1983; 46: 1115-8.

10 Kawimbe BM, Binnie NR, Smith AN. An electromyographically derived (anismus) index in pelvic floor outlet obstrucally derived (anismus) index in pelvic floor outlet obstrut
tion during defaecation straining. Gut 1988; 29: Al487.

11 Rutter KRP. Electromyographic changes in certain pelvic floor abnormalities. Proc $R$ Soc Med 1974; 67: 53 .

12 Jones PN, Lubowski DZ, Swash M, Henry MM. Is paradoxidal contraction of puborectalis muscle of functional importance? Dis Colon Rectum 1987; 30: 667-70.

13 Womack NR, Williams NS, Holmfield JH, Morrison JF Ano-rectal function in solitary rectal ulcer syndrome. Dis Ano-rectal function in solitary
Colon Rectum 1987; 30: 319-23.

14 Martin CJ, Parks TG. Solitary rectal ulcer syndrome in Northern Ireland 1971-1980. Br f Surg 1981; 68: 744-7.

15 Mahieu P, Prinjot J, Bodart P. Defecography: II. Contribution to the diagnosis of defaecation disorders. Gastrointest Radiol 1984; 9: 253-6.

16 Henry MM, Parks AG, Swash M. Electrophysiological and histological studies of the pelvic floor in descending perineum syndrome. Br $\mathcal{F}$ Surg 1982; 69: 470-2.

17 Hallan RI, Williams NS, Melling J, et al. Treatment of anismus in intractable constipation with botulinum $A$ toxin. Lancet 1988; ii: 714-7.

18 Wallace WC, Madden WM. Experience with partial resection of puborectalis muscle. Dis Colon Rectum 1969; 12: 196-200.

19 Barnes PRH, Hawley PR, Preston DM, Lennard-Jones JE. Experience of posterior division of the pubo-rectalis muscle in the management of chronic constipation. Br f Surg 1985; 72: 475-8.

20 Felt-Bersma RJF, Luth WJ, Janssen JJWM, Meuwissen GM Defecography in patients with anorectal disorders: which findings are clinically relevant? Dis Colon Rectum 1990; 33: 277-84. 